\title{
El efecto de la exposición a los sondeos preelectorales en el comportamiento de los votantes en las elecciones autonómicas en Andalucía de 2018
}

\author{
José María Ramírez Dueñas \\ María Lourdes Vinuesa Tejero \\ Universidad Complutense de Madrid. Facultad de Ciencias de la Información. Sección \\ Departamental de Sociología Aplicada \\ josemara@ucm.es; mlourdes@ucm.es \\ ORCID: https://orcid.org/0000-0002-4760-4034; https://orcid.org/0000-0002-9315-9170
}

Recepción: 17-04-2019

Aceptación: 31-05-2020

Publicación: 28-09-2020

\section{Resumen}

Los sondeos preelectorales se han convertido en una herramienta de comunicación política para partidos políticos y medios de comunicación. Este trabajo ha pretendido estudiar el efecto de la exposición a las encuestas en el comportamiento electoral de los votantes para las elecciones autonómicas de Andalucía de 2018. Los muchos sondeos publicados por los medios de comunicación ofrecieron unas expectativas excesivamente optimistas para el Partido Socialista y generaron un escenario de alta competitividad entre partidos conservadores (Partido Popular, Ciudadanos y Vox), lo que afectó a las preferencias electorales de los votantes. Mediante un modelo estadístico en dos fases, hemos comprobado que se produjo una movilización en el electorado socialista dada la probabilidad de una mayoría sólida; así como que los votantes conservadores se declinaron por realizar un voto ideológico (Vox) frente a un voto estratégico (Partido Popular), debido a una falta de mayorías alternativas al gobierno socialista de Susana Díaz.

Palabras clave: campaña electoral; comportamiento electoral; Andalucía; medios de comunicación; abstención; Partido Socialista; Susana Díaz 
Abstract. The effect of exposure to pre-election polls in the behavior of voters in the regional elections in Andalusia in 2018

Pre-election polls have become a tool of political communication for political parties and the media. This study has tried to study the effect of exposure to polls on the electoral behavior of voters for the 2018 Andalusian regional elections. The proliferation of polls published by the media offered overly optimistic expectations for the Socialist Party, and a scenario of high competitiveness between conservative parties (the Popular Party, the liberal party Ciudadanos and the right wing populist party Vox) that affected the electoral preferences of voters. Through a statistical model in two phases, we have verified how mobilization took place in the socialist electorate given the probability of a solid majority, and opting conservative voters to make an ideological vote (Vox) against a strategic vote (Popular Party), due to a lack of alternative majorities to the socialist government of Susana Díaz.

Keywords: electoral campaign; voting behavior; Andalusia; communication media; abstention; Socialist Party; Susana Díaz

\author{
Sumario \\ 1. Introducción 4. Metodología de trabajo \\ 2. Marco teórico 5. Resultados \\ 3. Hipótesis de trabajo 6. Conclusiones \\ Referencias bibliográficas
}

\title{
1. Introducción
}

Las campañas electorales son el escenario donde los agentes políticos implicados (ciudadanos, partidos, líderes, medios de comunicación...) ejercen su influencia en la opinión pública. Este influjo es especialmente relevante en los procesos de formación y orientación del voto de los electores, al ser el espacio de convergencia de todos estos actores de la vida política. Uno de los principales protagonistas de los periodos preelectorales son las encuestas, porque contribuyen a la información de la opinión pública, pero también a su persuasión, manipulación y control debido a problemas metodológicos (Monzón, 2000; 2005), o a la desinformación debido a problemas en su metodología o al procesamiento de los datos (Font Fàbregas y Pasadas del Amo, 2016; Bandera López, 2016).

Por tanto, estas técnicas de medición de las opiniones han sido una herramienta de comunicación política que ha servido a medios y partidos políticos para influir en los ciudadanos, especialmente en escenarios donde existe alta competitividad electoral, tal y como sucedió en las elecciones autonómicas andaluzas del 2 de diciembre de 2018. Estos comicios son especialmente interesantes ya que con ellos se ha puesto fin a casi cuarenta años de gobierno 
del Partido Socialista de Andalucía (PSOE-A), al facilitar Ciudadanos y Vox un gobierno del Partido Popular, con Juan Manuel Moreno Bonilla como presidente de la Junta de Andalucía. Estos comicios aportan interés académico debido a la representación parlamentaria obtenida por primera vez en el ámbito regional de un partido populista de extrema derecha — right wing populist parties (RWPP). Vox, a pesar de no compartir la base electoral y el contenido programático de los partidos de esta familia que han crecido en la Unión Europea en las dos últimas décadas (Bornschier, 2010; Santana y Rama, 2018), ha tenido una especial relevancia en la fragmentación en el sistema de partidos nacional a partir de las convocatorias electorales nacionales de abril y de noviembre de 2019.

En ese sentido, además de la importancia que tienen tales comicios para la ciencia política, también debe observarse en ellos dos aspectos especialmente relevantes para su estudio bajo un enfoque sociológico. En primer lugar, por el protagonismo que han pretendido jugar las encuestas preelectorales en esa campaña electoral, más cuando dicha campaña estuvo protagonizada por la posibilidad de mayorías parlamentarias alternativas al Gobierno socialista. A este respecto, los medios de comunicación regionales y nacionales utilizaron los sondeos preelectorales como una herramienta de comunicación política para modelar las preferencias electorales de los ciudadanos, dentro de la teoría sociológica denominada "espiral del silencio», de E. NoelleNeumann (1974; 1984).

En segundo lugar, porque, a pesar de la divulgación de un gran número de encuestas preelectorales en las dos semanas previas a la campaña electoral, como posteriormente comentaremos, las previsiones se alejaron de manera considerable de los resultados electorales que finalmente obtuvieron los partidos políticos, bien porque la campaña electoral afectó claramente a las preferencias electorales de los ciudadanos, bien porque estas encuestas electorales tenían como objetivo formar una opinión electoral distinta a la que realmente acontecía.

El principal objetivo de esta investigación es analizar la función que tuvieron estos sondeos preelectorales en la configuración de la opinión pública y los procesos de formación del voto, dentro de esta trayectoria de modelación de las preferencias electorales descrita en la teoría sociológica que conocemos como espiral del silencio en el marco de las elecciones autonómicas andaluzas. ¿¿De qué manera influenciaron las previsiones demoscópicas en el comportamiento electoral de los andaluces en estos comicios? ¿Motivaron la desmovilización o desactivación de una parte del electorado? ¿Provocaron una conversión estadísticamente relevante de votantes de un partido a otro?

Para responder a estas preguntas, hemos desarrollado un modelo para estudiar los efectos de las encuestas preelectorales en las elecciones autonómicas en Andalucía de 2018. La investigación que aquí planteamos analiza el papel que tuvieron los sondeos en la campaña electoral y cuáles fueron las consecuencias político-electorales de la exposición a las encuestas en los procesos de activación y movilización en el voto en las elecciones autonómicas andaluzas. 


\section{Marco teórico}

\subsection{Sondeos y clima de opinión preelectoral en Andalucía}

Como hemos comentado en la introducción, las encuestas preelectorales pretendieron tener un papel significativo en la estrategia electoral de los partidos en las elecciones andaluzas de 2018. Durante toda la campaña electoral, se han contabilizado los 16 principales sondeos publicados, elaborados por institutos demoscópicos públicos y privados y difundidos por los medios de comunicación, sobre todo a escala nacional; a los que habría que sumar una decena más durante las semanas previas que no recogemos en este trabajo. En todos, hemos diagnosticado tamaños de muestra muy variables (desde las 1.800 entrevistas de GAD3 a las 5.000 de Metroscopia) y errores muestrales con rangos del $+/-1,4 \mathrm{al}+/-2,4 \%$.

En las siguientes tablas ( 1 y 2 ), en primer lugar hemos reflejado los porcentajes de voto pronosticados y los escaños atribuidos a los cinco partidos. En ese sentido, la primera conclusión que podemos sacar es que las encuestas electorales vaticinaban una nueva e indiscutible victoria de los socialistas en esas elecciones regionales, sin posibilidad de gobierno alternativo que no pasará por el PSOE-A, junto con uno de los otros partidos.

Los rangos de porcentaje de votos señalaban unas distancias muy pronunciadas: $30-35 \%$ de voto para el PSOE-A; un empate entorno al $20 \%$ para el Partido Popular y Ciudadanos; Adelante Andalucía se quedaba ligeramente por detrás de estos, con un 18-19\%, y Vox, por debajo del 5\%. Hasta el final de la campaña - no olvidemos que en los últimos días la ley electoral no permite publicar encuestas - no se vislumbró la posibilidad de la presencia de este último partido en el Parlamento andaluz. Respecto a los escaños atribuidos, los rangos son levemente más amplios y reproducen las diferencias porcentuales de los índices de voto: PSOE-A, entre 40 y 45 escaños; PP, 24-27; Ciudadanos, 20-23; Adelante Andalucía, 20-23, y Vox, 0-2 (con posibilidad de escaño en los sondeos publicados los últimos días de campaña).

En ese sentido, el clima de opinión (en términos de Noelle-Neumaan, 1984) estaba perfectamente definido. Los socialistas podrían volver a formar gobierno como en 2015 con dos aliados: o virar hacia la izquierda con Adelante Andalucía (la presidenta de Andalucía había tenido bruscos enfrentamiento con esta coalición) o reeditar su pacto de legislatura con Ciudadanos. No había más alternativas a este escenario, salvo en uno de los sondeos (El Español), donde la suma de mayorías quedaba algo más ajustada, cercana a la posibilidad de que las tres fuerzas a la derecha del PSOE-A (PP, Ciudadanos y Vox) llegaran a la mayoría absoluta.

Las encuestas ofrecían un escenario de alta competitividad por los votantes conservadores, en el sentido de que en algún escenario Ciudadanos podría arrebatarle el liderazgo de la oposición al Partido Popular. En cambio, la probabilidad de la entrada de Vox en el Parlamento andaluz era más bien escasa. 
Tabla 1. Porcentajes de voto atribuido a los diferentes partidos en las encuestas preelectorales durante la campaña electoral.

\begin{tabular}{llllllll}
\hline Medio & Tipo & Fecha & PSOE-A & PP & Ciudadanos & AA* & Vox \\
\hline CIS & Organismo & $14 / 11 / 18$ & 37,40 & 18,68 & 18,45 & 19,34 & 3,17 \\
Publicaciones del SurNVivaa & Prensa & $15 / 11 / 18$ & 30,40 & 19,80 & 20,60 & 17,50 & 4,20 \\
ABC & Prensa & $17 / 11 / 18$ & 33,50 & 22,30 & 19,50 & 17,40 & 3,60 \\
Público & Online & $18 / 11 / 18$ & 33,40 & 21,60 & 20,60 & 18,30 & 0,50 \\
Antena 3 & Televisión & $19 / 11 / 18$ & 32,00 & 22,20 & 19,20 & 18,60 & 3,60 \\
El Español (.com) & Online & $19 / 11 / 18$ & 30,60 & 21,20 & 19,00 & 20,40 & 5,60 \\
El Diario de Sevilla & Prensa & $19 / 11 / 18$ & 30,90 & 20,10 & 21,20 & 20,90 & 3,00 \\
La Razón & Prensa & $19 / 11 / 18$ & 34,60 & 22,80 & 15,50 & 21,10 & 2,00 \\
La Voz de Almería & Prensa & $25 / 11 / 18$ & 35,90 & 21,80 & 14,60 & 21,10 & 3,10 \\
El País & Prensa & $25 / 11 / 18$ & 32,10 & 20,00 & 18,00 & 19,00 & 4,30 \\
El Diario (.es) & Online & $26 / 11 / 18$ & 35,80 & 21,60 & 15,00 & 21,20 & 3,20 \\
El Español (.com) & Online & $25 / 11 / 18$ & 32,80 & 22,70 & 16,20 & 18,60 & 6,50 \\
La Razón & Prensa & $25 / 11 / 18$ & 34,50 & 22,30 & 14,80 & 21,40 & 3,80 \\
ABC & Prensa & $26 / 11 / 18$ & 32,60 & 20,70 & 19,30 & 17,60 & 6,80 \\
La Sexta & Televisión & $26 / 11 / 18$ & 33,00 & 22,20 & 19,70 & 19,50 & 3,20 \\
La Voz de Almería & Prensa & $26 / 11 / 18$ & 36,00 & 24,90 & 13,20 & 18,20 & 2,80 \\
Medias & & & 33,46 & 21,55 & 17,80 & 19,38 & 3,71 \\
Resultado real & & & 27,95 & 20,75 & 18,27 & 16,18 & 10,97 \\
\hline
\end{tabular}

${ }^{*} \mathrm{AA}=$ Adelante Andalucía.

Fuente: elaboración propia.

Tabla 2. Escaños atribuidos a los diferentes partidos en las encuestas preelectorales durante la campaña electoral

\begin{tabular}{llcccccc}
\hline Medio & Tipo & Fecha & PSOE-A & PP & Ciudadanos & AA $^{*}$ & Vox \\
\hline CIS & Organismo & $14 / 11 / 18$ & $45-47$ & $20-22$ & $20-22$ & 20 & 1 \\
Publicaciones del Sur/Viva & Prensa & $15 / 11 / 18$ & $39-41$ & $24-26$ & $25-27$ & $19-21$ & 2 \\
ABC & Prensa & $17 / 11 / 18$ & $41-42$ & $25-27$ & $22-25$ & $17-19$ & $0-1$ \\
Público & Online & $18 / 11 / 18$ & 41 & 25 & 23 & 20 & 0 \\
Antena 3 & Televisión & $19 / 11 / 18$ & $38-41$ & $26-29$ & $22-23$ & $19-20$ & 0 \\
El Español (.com) & Online & $19 / 11 / 18$ & $36-38$ & $24-26$ & $21-23$ & $22-24$ & $1-3$ \\
El Diario de Sevilla & Prensa & $19 / 11 / 18$ & $37-40$ & 24 & $22-24$ & $23-24$ & 0 \\
La Razón & Prensa & $19 / 11 / 18$ & $40-43$ & $26-28$ & $16-18$ & $23-24$ & 0 \\
La Voz de Almería & Prensa & $25 / 11 / 18$ & $43-45$ & $26-27$ & $15-17$ & $23-24$ & $0-1$ \\
El País & Prensa & $25 / 11 / 18$ & $39-42$ & $22-26$ & $19-22$ & $22-24$ & $0-4$ \\
El Diario (.es) & Online & $26 / 11 / 18$ & $43-45$ & $26-27$ & $16-17$ & $23-24$ & $0-1$ \\
El Español (.com) & Online & $25 / 11 / 18$ & $37-40$ & $26-29$ & $17-20$ & $20-22$ & $3-5$ \\
La Razón & Prensa & $25 / 11 / 18$ & $41-43$ & $26-29$ & $15-17$ & $23-25$ & $0-2$ \\
ABC & Prensa & $26 / 11 / 18$ & $41-43$ & $24-25$ & $20-22$ & $17-19$ & $3-4$ \\
La Sexta & Televisión & $26 / 11 / 18$ & 41 & 26 & 20 & 21 & 1 \\
La Voz de Almería & Prensa & $26 / 11 / 18$ & $44-48$ & $30-33$ & $13-16$ & $19-22$ & $0-3$ \\
Resultado real & & & 33 & 26 & 21 & 17 & 12 \\
\hline AA Ad Adan & & & & & & &
\end{tabular}

${ }^{*} \mathrm{~A} A$ = Adelante Andalucía.

Fuente: elaboración propia. 
Tabla 3. Desviaciones entre porcentaje de voto atribuido por sondeos frente al real

\begin{tabular}{lccrrrr}
\hline Medio & Fecha & PSOE-A & PP & Ciudadanos & AA $^{*}$ & Vox \\
\hline CIS & $14 / 11 / 18$ & 9,45 & $-2,07$ & 0,18 & 3,16 & $-7,8$ \\
Publicaciones del Sur/Viva & $15 / 11 / 18$ & 2,45 & $-0,95$ & 2,33 & 1,32 & $-6,77$ \\
ABC & $17 / 11 / 18$ & 5,55 & 1,55 & 1,23 & 1,22 & $-7,37$ \\
Público & $18 / 11 / 18$ & 5,45 & 0,85 & 2,33 & 2,12 & $-10,47$ \\
Antena 3 & $19 / 11 / 18$ & 4,05 & 1,45 & 0,93 & 2,42 & $-7,37$ \\
El Español (.com) & $19 / 11 / 18$ & 2,65 & 0,45 & 0,73 & 4,22 & $-5,37$ \\
El Diario de Sevilla & $19 / 11 / 18$ & 2,95 & $-0,65$ & 2,93 & 4,72 & $-7,97$ \\
La Razón & $19 / 11 / 18$ & 6,65 & 2,05 & $-2,77$ & 4,92 & $-8,97$ \\
La Voz de Almería & $25 / 11 / 18$ & 7,95 & 1,05 & $-3,67$ & 4,92 & $-7,87$ \\
El País & $25 / 11 / 18$ & 4,15 & $-0,75$ & $-0,27$ & 2,82 & $-6,67$ \\
El Diario (.es) & $26 / 11 / 18$ & 7,85 & 0,85 & $-3,27$ & 5,02 & $-7,77$ \\
El Español (.com) & $25 / 11 / 18$ & 4,85 & 1,95 & $-2,07$ & 2,42 & $-4,47$ \\
La Razón & $25 / 11 / 18$ & 6,55 & 1,55 & $-3,47$ & 5,22 & $-7,17$ \\
ABC & $26 / 11 / 18$ & 4,65 & $-0,05$ & 1,03 & 1,42 & $-4,17$ \\
La Sexta & $26 / 11 / 18$ & 5,05 & 1,45 & 1,43 & 3,32 & $-7,77$ \\
La Voz de Almería & $26 / 11 / 18$ & 8,05 & 4,15 & 13,2 & 2,02 & $-8,17$ \\
\hline Media & & 5,24 & 0,62 & 0,50 & 3,45 & $-7,09$ \\
(Desviación típica) & & $(2,07)$ & $(1,69)$ & $(3,61)$ & $(1,33)$ & $(1,43)$ \\
\hline
\end{tabular}

${ }^{*} \mathrm{AA}=$ Adelante Andalucía.

Fuente: elaboración propia.

Tabla 4. Desviaciones entre escaños atribuidos por sondeos frente a los reales

\begin{tabular}{lcrrrrr}
\hline Medio & Fecha & PSOE-A & PP & Ciudadanos & AA $^{*}$ & Vox \\
\hline CIS & $14 / 11 / 18$ & 13,0 & $-5,0$ & 0,0 & 3,0 & $-11,0$ \\
Publicaciones del Sur/Viva & $15 / 11 / 18$ & 7,0 & $-1,0$ & 5,0 & 3,0 & $-10,0$ \\
ABC & $17 / 11 / 18$ & 8,5 & 0,0 & 2,5 & 1,0 & $-11,5$ \\
Público & $18 / 11 / 18$ & 8,0 & $-1,0$ & 2,0 & 3,0 & $-12,0$ \\
Antena 3 & $19 / 11 / 18$ & 6,5 & 1,5 & 1,5 & 2,5 & $-12,0$ \\
El Español (.com) & $19 / 11 / 18$ & 4,0 & $-1,0$ & 1,0 & 6,0 & $-10,0$ \\
El Diario de Sevilla & $19 / 11 / 18$ & 5,5 & $-2,0$ & 2,0 & 6,5 & $-12,0$ \\
La Razón & $19 / 11 / 18$ & 8,5 & 1,0 & $-4,0$ & 6,5 & $-12,0$ \\
La Voz de Almería & $25 / 11 / 18$ & 11,0 & 0,5 & $-5,0$ & 5,5 & $-10,5$ \\
El País & $25 / 11 / 18$ & 7,5 & $-2,5$ & $-0,5$ & 6,0 & $-10,0$ \\
El Diario (.es) & $26 / 11 / 18$ & 11,0 & 0,5 & $-4,5$ & 6,5 & $-11,5$ \\
El Español (.com) & $25 / 11 / 18$ & 5,5 & 1,5 & $-2,5$ & 4,0 & $-8,0$ \\
La Razón & $25 / 11 / 18$ & 9,0 & 1,5 & $-5,0$ & 7,0 & $-11,0$ \\
ABC & $26 / 11 / 18$ & 9,0 & $-1,5$ & 0,0 & 1,0 & $-8,5$ \\
La Sexta & $26 / 11 / 18$ & 8,0 & 0,0 & $-1,0$ & 4,0 & $-11,0$ \\
La Voz de Almería & $26 / 11 / 18$ & 13,0 & 5,5 & $-6,5$ & 3,5 & $-10,5$ \\
\hline Media & & 7,93 & $-0,32$ & $-0,54$ & 4,55 & $-10,91$ \\
(Desviación típica) & & $(2,74)$ & $(2,65)$ & $(3,72)$ & $(2,34)$ & $(1,27)$ \\
\hline
\end{tabular}

${ }^{*} \mathrm{~A} A=$ Adelante Andalucía.

Fuente: elaboración propia. 
Sin embargo, como advertíamos, los resultados electorales estuvieron algo alejados de los pronósticos de los sondeos preelectorales La discordancia entre los pronósticos y los datos de los comicios fue muy palpable. Sobre los porcentajes de voto, se observan dos desviaciones principales: en el Partido Socialista (PSOE-A), donde la media se aleja en cinco puntos y medio, y en Vox, donde la diferencia supera los siete puntos. En el resto de partidos, los resultados estuvieron dentro de los límites de error.

Además, las atribuciones de escaños previstas en el Parlamento se alejaron aún más que los porcentajes de índice de voto, por lo que recrearon una escenario poselectoral que no se correspondió con los resultados. Ninguna encuesta adelantó los resultados del PSOE-A (33 escaños, cuando en la mayoría los pronósticos superaban los 40) ni tampoco los de Vox (12 escaños, cuando en la mayoría de las encuestas no se vaticinaba representación y solo una ofrecía la posibilidad de 5 escaños). Y, por supuesto, solo una pronosticó la mayoría alternativa resultante al gobierno del Partido Socialista.

La disparidad entre resultados y pronósticos podría deberse a escasas muestras, metodologías de análisis exclusivamente cuantitativas o sin tener en cuenta la serie histórica de cada circunscripción electoral. De ahí la complejidad de atribuir escaños en sondeos preelectorales, que ya ha sido ampliamente estudiada en otros procesos electorales (Delicado y Udina, 2001; Mateos y Penadés, 2013; Caballé et al., 2013).

\subsection{Los efectos políticos de los sondeos electorales}

Las campañas electorales se han vuelto cada vez más decisivas en el proceso de orientación del voto de los ciudadanos y en la formación de la opinión pública (Martínez i Coma, 2008; Barreiro et al., 2014; entre otros). En detrimento de las teorías clásicas de orientación de voto (Escuela de Colombia, Michigan y Rochester), que han servido para explicar el comportamiento electoral durante las últimas décadas, es en las campañas donde cada vez un mayor número de electores decide su voto, especialmente durante la última semana.

Los sondeos preelectorales son uno de los agentes más relevantes de las campañas electorales, ya que generan flujos de información más detallada y comprensible para los ciudadanos para que estos pueda ejercer su voto de manera más eficiente (Gasperoni y Mantovani, 2015). A pesar de no gozar de la mejor de las valoraciones por parte de los ciudadanos, que las desdeñan por su falta de precisión y transparencia (Fernández y Vinuesa, 2014), son uno de las instrumentos más presentes en la agenda pública y más utilizados por los medios de comunicación.

Cuando se ponen en circulación, permiten a los ciudadanos aumentar la información y el conocimiento de los candidatos y ofrecerles estrategias en el momento de escoger entre las distintas opciones electorales (Donsbach, 2001; Lau y Redlaswsk, 2006). De ahí que su inclusión como herramienta del gobierno democrático ha suscitado desde siempre opiniones muy encontradas. Pese a que algunos autores han minusvalorado sus efectos en el comportamiento 
electoral (Daschmann, 2000), el consenso académico ha determinado que la exposición a los sondeos preelectorales sirve a los ciudadanos para configurar sus preferencias electorales (Bock, 1976; Lavrakas et al., 1991; Holtz-Bacha y Strömbäck, 2012). Los académicos han investigado cómo los votantes utilizan la información de las encuestas para determinar sus decisiones cuando participan en las elecciones, en la línea de lo que los sociólogos clásicos (Gallup y Rae, 1940; Likert, 1948) defendían como una herramienta de información de la opinión pública para controlar a los gobiernos.

Los medios de comunicación, como principal fuente de información política, marcan la agenda temática (teoría de la agenda setting) y orientan a la opinión pública (framing y priming). De ahí que numerosos autores hayan estudiado los efectos perniciosos de los sondeos electorales y su importancia en la vida política como herramientas de comunicación política (Noelle-Neumann, 1984; Skalaban, 1988; Broughton, 1995; Gasperoni y Mantovani, 2015), su instrumentalización para fines electorales (Monzón, 2005), y la utilización de los sesgos por parte de los medios de comunicación y casos encuestadores para imputar votantes indecisos y abstencionistas a distintas opciones electorales (McEwen, 2004; Cabrera-Allvarez y Escobar, 2019). Por ello, la investigación ha constatado que los efectos de los sondeos pueden verse reducidos si con anterioridad empiezan a fallar considerablemente en las previsiones, o si los votantes consideran que detrás de los resultados existen intenciones partidistas o ideológicas para alterar su comportamiento electoral.

\section{Hipótesis de trabajo}

Con el contexto preelectoral descrito en el epígrafe anterior y la práctica unanimidad de sondeos apuntando hacia una mayoría del Partido Socialista, con dos posibles socios de gobierno - o bien revalidando el pacto de la pasada legislatura con Ciudadanos, o bien virando hacia la izquierda con Adelante Andalucía-, el clima de opinión era favorable a este partido. Nuestra hipótesis de partida (H1) asume un papel predominante de los sondeos en la movilización electoral de sus votantes.

Hipótesis 1 (H1): La probabilidad de votar al PSOE-A será más probable en aquellos votantes expuestos a los sondeos electorales.

Esta hipótesis está fundamentada en torno a dos principios. En primer lugar, si los votantes generalmente realizan un seguimiento de los sondeos para tomar la decisión (planteado en Hummel, 2014: 78-79), las encuestas electorales ayudarían a elegir a los candidatos o partidos con mayores posibilidades de ganar o de formar gobiernos estables (Carpini, 1984; Lavrakas et al. 1991), con el clima de opinión favorable para este partido. Las dudas acerca de la rentabilidad electoral de su voto (en términos de Downs, 1957) quedarían disipadas dada la posibilidad de revalidar su mayoría por otro periodo legislativo.

Siguiendo además con esta idea, el favorable clima de opinión podría suponer un posible efecto arrastre de aquellos ciudadanos indecisos para unirse «al 
carro ganador». El llamado efecto bandwagon o arrastre (McAllister y Studlar, 1991; Nadeau et al., 1994; Mehrabian, 1998; Kiss y Simonovits, 2014; Grillo, 2017) ofrece a los votantes indecisos alinear sus propias preferencias de voto con las intenciones de la mayoría del cuerpo electoral: cuando un candidato tiene el apoyo de la mayoría, el mecanismo psicológico de los votantes se activa. En ese sentido, los sondeos preelectorales no son el único activador, sino que las características y competencias del candidato interfieren en los electores (Obermaier et al., 2017), así como el coste de oportunidad de participar o abstenerse. En las primeras teorías del voto económico racional, Downs (1957) ya planteaba que muchos votantes, en ausencia de información para tomar la mejor decisión, podrían deducir la mejor elección racionalmente imitando a otros electores. Así pues, los sondeos preelectorales serían un sistema de mediación que otorga más información acerca del candidato con mayores posibilidades de ganar (Hopmann et al., 2010; Dahlgaard et al., 2016), como sucedía en este caso con el Partido Socialista, con condiciones de victoria por encima de los 40 diputados y sin mayoría alternativa posible. Los electores manejan la información procedente de las encuestas preelectorales para realizar un voto estratégico, de modo que puedan maximizar su voto (Duverger, 1954; Rich, 2015).

Si las expectativas electorales del PSOE-A fueron tales, nuestra hipótesis complementaria a la primera es que los votantes de Adelante Andalucía estuvieran menos expuestos a los sondeos, dado que ambas formaciones comparten base electoral.

Subhipótesis 1.1 (H1.1): La probabilidad de votar a Adelante Andalucía aumentará en aquellos votantes no expuestos a los sondeos electorales.

Con respecto a las otras tres formaciones (Partido Popular, Ciudadanos y Vox), contemplamos dos hipótesis de trabajo. Carpini (1984) y Moy y Rinke (2012) han expuesto que el consumo de encuestas en campaña electoral puede influenciar la participación (movilización) o la abstención de votantes (desmovilización), especialmente en escenarios electorales de alta competitividad entre dos partidos con candidatos o partidos con similares niveles de apoyo. El clima de opinión anteriormente expuesto narraba la competitividad de dos formaciones - el Partido Popular y Ciudadanos - por conseguir la segunda plaza, pero en cierta manera se daba por segura la victoria de los socialistas. En ese sentido, creemos que los votantes se informaron para observar cuál sería el voto estratégico más rentable.

Hipótesis 2 (H2): La probabilidad de votar a Ciudadanos y al Partido Popular será más probable en aquellos votantes expuestos a los sondeos electorales.

Gasperoni y Mantovani (2015: 3) detallan los cambios preferenciales de los votantes en contextos multipartidistas como modelos estratégicos de elección de la opción electoral más efectiva para sus intereses particulares. Principalmente, estos efectos podrían reducirse a la activación o la conversión de los electores indecisos. Dada la posibilidad de voto, queremos contrastar si la 
hipótesis de la competitividad electoral incentiva la exposición de los ciudadanos a los sondeos.

$\mathrm{Al}$ contrario, las expectativas electorales de Vox eran poco favorables. Como hemos comentado, eran pocos los sondeos preelectorales que auguraban su entrada en el Parlamento, y solo dos les daban una representación por encima de los tres diputados. En ese sentido, tomamos como hipótesis que los votantes de este partido tuvieron una actitud más ideológica frente al voto estratégico que realizaron los votantes del Partido Popular y Ciudadanos.

Hipótesis 3 (H3): La probabilidad de votar a Vox aumentará en aquellos votantes no expuestos a los sondeos electorales.

\section{Metodología de trabajo}

Para cumplir con los objetivos marcados, así como para poder dar respuestas a nuestras preguntas, la investigación ha partido de la recogida de todas las encuestas preelectorales publicadas durante la campaña electoral analizada (elecciones andaluzas de 2018), tal y como hemos mostrado en las tablas 1 y 2. Estas investigaciones son un instrumento que no solamente no indica las preferencias de los ciudadanos en función del desarrollo de la campaña, sino que además, tal y como hemos recogido en el marco teórico (Bock, 1976; Lavrakas et al., 1991; Holtz-Bacha y Strömbäck, 2012; entre otros), parecen tener relevancia en la orientación del voto de los ciudadanos, y para nuestro caso de análisis, de los andaluces.

Tras la recogida y el análisis de estos estudios, parece constatado que el número de encuestas a todos los niveles fue mayor que en otras campañas electorales autonómicas en la comunidad, que el clima de opinión generado fue claro (mayoría socialista y revalidación de gobierno), y que existió una disonancia entre lo vaticinado por las encuestas preelectorales y lo que arrojaron los resultados.

Con estos datos de partida, y como hemos comentado, para cumplir con nuestros objetivos y responder nuestras preguntas de investigación, hemos diseñado un modelo de análisis basado en la muestra de la encuesta poselectoral ( $n .^{\circ}$ 3.236) del Centro de Investigaciones Sociológicas ( $\mathrm{N}=2.913$ encuestados) para observar qué efectos tuvo la exposición selectiva a estos sondeos durante la campaña electoral en el voto de los ciudadanos de Andalucía.

La información obtenida permitirá someter a verificación nuestras hipótesis sobre si la exposición a las encuestas condiciona o no la orientación del voto respecto a las cinco formaciones políticas mencionadas. Para ello, se ha procedido a adecuar la formulación de las variables dependientes e independientes a las necesidades de nuestra investigación mediante la transformación y la combinación de estas (Crespo et al. 2015).

En primer lugar, nuestra variable dependiente viene determinada por la probabilidad de participar en las elecciones o haber votado a los diferentes partidos con representación parlamentaria. Para ello, hemos recodificado de una 
manera dicotómica cada una de ellas: la participación electoral (0) o abstención (1), y el voto a las formaciones políticas seleccionadas - Partido Socialista de Andalucía (PSOE-A); Partido Popular (PP); Podemos e Izquierda Unida, en Adelante Andalucía (AA); Ciudadanos, y Vox. Aquí el valor otorgado ha sido no voto (0) y voto al partido o formación política (de entre las cinco mencionadas) con valor (1). De esta forma, podemos observar si cualquiera de las variables independientes tuvo una función en la configuración de la opinión pública y los procesos de formación del voto en esta campaña electoral, más concretamente el papel de los sondeos preelectorales.

Sobre estas variables dependientes, hemos desarrollado dos análisis con un conjunto de variables independientes y de control. En el primero, solo se han aplicado una serie de variables clásicas en el comportamiento electoral.

A) Variables sociodemográficas: edad (numérica, de 1-96 años), sexo (hombre o mujer), estatus socioeconómico (según refleja el CIS, en sus cinco categorías: clase alta/media-alta, nuevas clases medias, viejas clases medias, obreros cualificados y obreros no cualificados), el nivel educativo (en cuatro categorías: sin estudios, estudios primarios, secundarios y superiores) y el tamaño del municipio (con seis tipos de hábitat diferentes, clarificados y descritos en la tabla 5).

B) Variables político-ideológicas: grado de interés en la campaña (desde "con mucho interés» a "ningún interés»), la autoubicación en la escala ideológica $^{1}$. Para los análisis de efectos marginales posteriores, también se ha utilizado la simpatía (dicotómica) por los diferentes partidos.

C) Valoración de líderes. En el modelo, se ha incluido la evaluación de los dos incumbents (del presidente del Gobierno, Pedro Sánchez, y de la presidenta de Andalucía, Susana Díaz, ambos del PSOE), así como la del candidato a la Junta del partido al que votó el encuestado.

En el segundo modelo de análisis, a estas variables se ha incorporado como variable independiente la «exposición» (conocimiento) a sondeos preelectorales que tuvieron los encuestados (p. $9^{2}$ ). Para ello, se ha tomado de manera dicotómica, con el valor 1 para aquellos votantes que se expusieron a la información electoral vertida por estos sondeos y el 0 para aquellos que no obtuvieron exposición. Aquellos que declararon "no sabe» o «no contesta» fueron descartados como perdidos.

En ese sentido, en el estudio de las encuestas electorales de la campaña sobrevuela la complejidad de asumir el autorreconocimiento por parte de los ciudadanos de la influencia de los sondeos sobre su propio voto. Así pues, hemos tomado como variable de análisis el conocimiento de los sondeos como

1. Para la recodificación de la variable «autoubicación ideológica», se han establecido cinco cohortes diferentes: izquierda (1-2), centro-izquierda (3-4), centro (5), centro-derecha (6-8) y derecha (9-10). Aquellos individuos que no contestaron la pregunta (NS/NC) se han considerado como perdidos.

2. «¿Y tuvo usted conocimiento de los resultados de alguna de las encuestas o sondeos preelectorales realizados antes de las elecciones?» 
Tabla 5. Variables del modelo de estudio

\begin{tabular}{|c|c|c|c|c|}
\hline Variable & $\mathrm{N}$ & Frecuencias & Media & Desviación estándar \\
\hline \multicolumn{5}{|l|}{ Dependientes } \\
\hline \multicolumn{5}{|l|}{ Abstención } \\
\hline 0- Participó & 2.151 & $73,9 \%$ & & \\
\hline 1- Abstención & 759 & $26,1 \%$ & & \\
\hline \multicolumn{5}{|l|}{ PSOE-A } \\
\hline 0- No votó & 565 & $80,6 \%$ & & \\
\hline 1- Votó al PSOE-A & 2.348 & $19,4 \%$ & & \\
\hline \multicolumn{5}{|l|}{ PP } \\
\hline 0- No votó & 2.613 & $89,7 \%$ & & \\
\hline 1- Votó al PP & 300 & $10,3 \%$ & & \\
\hline \multicolumn{5}{|l|}{ Ciudadanos } \\
\hline 0- No votó & 2.631 & $90,3 \%$ & & \\
\hline 1- Votó a Ciudadanos & 282 & $9,7 \%$ & & \\
\hline \multicolumn{5}{|l|}{ AA } \\
\hline 0- No votó & 2.632 & $90,3 \%$ & & \\
\hline 1- Votó a Adelante Andalucía & 281 & $9,7 \%$ & & \\
\hline \multicolumn{5}{|l|}{ Vox } \\
\hline 0- No votó & 2.791 & $95,8 \%$ & & \\
\hline 1- Votó a Vox & 122 & $4,2 \%$ & & \\
\hline \multicolumn{5}{|l|}{ Independientes } \\
\hline \multicolumn{5}{|l|}{ Conocimiento de sondeos electorales } \\
\hline $0-\mathrm{No}$ & 1.435 & $49,3 \%$ & 0,49 & 0,50 \\
\hline 1- Sí & 1.473 & $59,7 \%$ & & \\
\hline \multicolumn{5}{|l|}{ Grado de interés en la campaña } \\
\hline 5- Con mucho interés & 289 & $9,9 \%$ & 2,58 & 1,377 \\
\hline 4- Con bastante interés & 687 & $23,6 x^{\circ} x^{\circ} \%$ & & \\
\hline 3- Ni con mucho ni con poco interés & 315 & $10,8 \%$ & & \\
\hline 2- Con poco interés & 765 & $26,3 \%$ & & \\
\hline 1- Con ningún interés & 853 & $29,3 \%$ & & \\
\hline \multicolumn{5}{|l|}{ Edad } \\
\hline Numérica, 18-96 años & 2.913 & $100 \%$ & 48,80 & 17,760 \\
\hline \multicolumn{5}{|l|}{ Sexo } \\
\hline 1- Hombre & 1.419 & $48,7 \%$ & & \\
\hline 0- Mujer & 1.494 & $51,3 \%$ & & \\
\hline \multicolumn{5}{|l|}{ Nivel de estudios } \\
\hline 1- Sin estudios & 227 & $7,8 \%$ & 2,86 & 0,825 \\
\hline 2- Primarios & 523 & $17,9 \%$ & & \\
\hline 3- Secundarios & 1.556 & $53,4 \%$ & & \\
\hline 4- Superiores & 594 & $20,5 \%$ & & \\
\hline Estatus socioeconómico & 496 & $17,5 \%$ & 3,12 & 1,406 \\
\hline 1- Clase alta/media-alta & 613 & $21,6 \%$ & & \\
\hline $\begin{array}{l}\text { 2- Nuevas clases medias } \\
\text { 3- Vieias clases medias }\end{array}$ & 334 & $11,8 \%$ & & \\
\hline $\begin{array}{l}\text { 3- Viejas clases medias } \\
\text { 4- Obreros cualificados }\end{array}$ & 842 & $29,7 \%$ & & \\
\hline 5- Obreros no cualificados & 552 & $19,5 \%$ & & \\
\hline
\end{tabular}


Tabla 5. Variables del modelo de estudio (continuación)

\begin{tabular}{|c|c|c|c|c|}
\hline Variable & $\mathrm{N}$ & Frecuencias & Media & Desviación estándar \\
\hline \multicolumn{5}{|l|}{ Independientes } \\
\hline Tamaño del municipio & & & & 1,435 \\
\hline $\begin{array}{l}\text { 1- Menos o igual a } 2.000 \text { habitantes } \\
\text { 2- } 2.001 \text { a } 10.000 \text { habitantes } \\
\text { 3- } 10.001 \text { a } 50.000 \text { habitantes } \\
\text { 4- } 50.001 \text { a } 100.000 \text { habitantes } \\
\text { 5- } 100.001 \text { a } 400.000 \text { habitantes } \\
6-400.001 \text { a } 1.000 .000 \text { habitantes }\end{array}$ & $\begin{array}{l}100 \\
475 \\
857 \\
404 \\
618 \\
459\end{array}$ & $\begin{array}{r}3,4 \% \\
16,3 \% \\
29,4 \% \\
13,9 \% \\
21,2 \% \\
15,7 \%\end{array}$ & 3,80 & \\
\hline \multicolumn{5}{|l|}{ Autoubicación ideológica } \\
\hline $\begin{array}{l}\text { 1- Izquierda } \\
\text { 2- Centro-izquierda } \\
\text { 3- Centro } \\
\text { 4- Centro-derecha } \\
\text { 5- Derecha }\end{array}$ & $\begin{array}{r}188 \\
882 \\
567 \\
572 \\
67 \\
\text { (Conoce }\end{array}$ & $\begin{array}{r}6,5 \% \\
30,3 \% \\
19,5 \% \\
19,6 \% \\
2,3 \% \\
\\
\text { (Conoce }\end{array}$ & 2,75 & 1,014 \\
\hline Valoración de líderes Escala 1 a 10 & y valora) & y valora) & & \\
\hline $\begin{array}{l}\text { Susana Díaz (PSOE-A) } \\
\text { Juan Manuel Moreno (PP) } \\
\text { Juan Marín (Ciudadanos) } \\
\text { Antonio Maíllo (IU-AA) } \\
\text { Teresa Rodríguez (Podemos-AA) } \\
\text { Francisco Serrano (Vox) } \\
\text { Pedro Sánchez (PSOE) }\end{array}$ & $\begin{array}{r}2.525 \\
1.730 \\
1.586 \\
1.396 \\
1.845 \\
887 \\
2.515\end{array}$ & $\begin{array}{r}86,8 \% \\
59,4 \% \\
54,5 \% \\
47,9 \% \\
63,3 \% \\
30,5 \% \\
86,3 \%\end{array}$ & $\begin{array}{l}3,64 \\
3,71 \\
4,12 \\
3,41 \\
3,56 \\
2,53 \\
3,7\end{array}$ & $\begin{array}{l}2,913 \\
2,793 \\
2,452 \\
2,691 \\
2,857 \\
2,767 \\
2,912\end{array}$ \\
\hline \multicolumn{5}{|l|}{ Simpatía } \\
\hline $\begin{array}{l}\text { PSOE } \\
\text { PP } \\
\text { Ciudadanos } \\
\text { Podemos } \\
\text { IU } \\
\text { Vox } \\
\text { Ninguno }\end{array}$ & $\begin{array}{r}149 \\
34 \\
58 \\
26 \\
11 \\
7 \\
597\end{array}$ & $\begin{array}{l}5,1 \% \\
1,2 \% \\
2 \% \\
0,9 \% \\
0,4 \% \\
0,2 \% \\
20,5 \%\end{array}$ & & \\
\hline
\end{tabular}

Fuente: elaboración propia.

variable de estudio. La motivación es, primero, operacional debido a que nos permite una mayor muestra (un 49,3\% de los encuestados admite haber conocido alguna encuesta preelectoral), con dos subgrupos de estudio similares, que si hubiéramos tomado la variable de autorreconocimiento de los efectos de los sondeos sobre su comportamiento electoral (p. 9A $\mathrm{A}^{3}$ ), ya que solo el 10,1\% de los votantes expuestos afirman que les afectaron mucho o bastante (es decir, entorno a un $5 \%$ de la muestra). Pero además, y pese a que esta variable pudiera no tener una cierta gradualidad entorno a los posibles efectos de los

3. «¿Y en qué medida tuvo en cuenta los resultados de esas encuestas a la hora de decidir qué iba a votar: mucho, bastante, poco o nada?». 
sondeos sobre los votantes, es la más adecuada para el estudio de su influencia en el voto en línea con la bibliografía consultada (McAllister y Studlar, 1991; Gasperoni y Mantovani, 2015).

También admitimos que una de las limitaciones de este trabajo se debe a que el Centro de Investigaciones Sociológicas no realizó encuesta panel: la encuesta pre y la poselectoral utilizaron muestras diferentes. En ese sentido, es complicado conocer los efectos de los sondeos cuando careceremos de la intención de voto en el inicio de la campaña electoral, del reconocimiento de voto en la poselectoral y si hay mecanismos psicológicos (por ejemplo, el conocimiento de los sondeos electorales) como movilizadores o activadores de tal decisión.

Además, y como ha podido observarse, el modelo de análisis para explicar el voto para las formaciones políticas (PSOE-A, PP, Ciudadanos...) carece de variables clásicas ya asentadas en el estudio sociológico (evaluaciones sobre la situación política y económica, temas de preocupación, valoraciones de gestión del gobierno saliente...). Pese a que nuestro análisis pretendía introducir estas cuestiones centrales en la escuela económica-racional (Downs, 1957; Key, 1966; Fiorina, 1981) y, más en concreto, en los enfoques retrospectivos (Maravall y Przeworski, 1999; Stokes, 2001; Duch y Stevenson, 2008; LewisBeck y Stegmaier, 2009, entre otros), carecemos de elementos para medir la satisfacción de los ciudadanos respecto a la performance y la gestión pública del gobierno saliente, y por tanto nuestras conclusiones estarán condicionadas a estas restricciones.

\section{Resultados}

Como hemos expuesto, los sondeos y las encuestas de opinión publicados por los medios de comunicación en la campaña electoral de las elecciones regionales en Andalucía tuvieron un papel protagonista como herramienta de comunicación política. Sin embargo, es importante observar la correlación entre opinión publicada y su traslación a la opinión pública. Y en ese sentido, la exposición que tuvieron los ciudadanos a estos sondeos no fue excesivamente alta (algo menos del $50 \%$ de los encuestados tuvo conocimiento de previsiones electorales), y su efectividad (autorreconocida por los propios votantes) dista de ser relevante (tabla 6): solo un $16 \%$ de los votantes admiten que los sondeos electorales tuvieron algún grado de influencia (ya sea mucho, bastante o poca) en su voto.

Los descriptivos de las variables independientes parecen denotar una mayor exposición a las encuestas preelectorales en los votantes encuadrados a la derecha en la escala de ubicación ideológica, especialmente del 6-8 (por encima del $60 \%$, frente al $50 \%$ de los votantes en el 3 o el 4). Si el impacto de la exposición a los sondeos preelectorales no es trasversal, sí observamos una mayor exposición a los sondeos en los votantes del Partido Popular y Vox (en términos de distancia ideológica entre autoubicación propia y posicionamiento medio de estos partidos en el eje izquierda-derecha). 
Tabla 6. Efectos en los votantes de los sondeos electorales durante la campaña electoral

\begin{tabular}{lcc}
\hline & Frecuencia & Porcentaje \\
\hline Mucho & 38 & $1,3 \%$ \\
Bastante & 106 & $3,6 \%$ \\
Poco & 324 & $11,1 \%$ \\
Nada & 958 & $32,9 \%$ \\
NS/NC & 8 & $0,3 \%$ \\
Total & 1.435 & $49,3 \%$ \\
Perdidos & 1.478 & $50,7 \%$ \\
(N) & $(2.913)$ & $100 \%$ \\
\hline
\end{tabular}

Fuente: elaboración propia a partir de la encuesta poselectoral n. ${ }^{\circ} 3.226$ del Centro de Investigaciones Sociológicas.

Tabla 7. Conocimiento de los resultados de sondeos electorales durante la campaña electoral según autoubicación ideológica

\begin{tabular}{lrccc}
\hline & $(\mathbf{N})$ & Sí & No & N. C. \\
\hline 1 Izquierda & 77 & 69,7 & 30,3 & - \\
2 & 111 & 54,1 & 45,9 & - \\
3 & 466 & 51,8 & 48,0 & 0,2 \\
4 & 415 & 52,9 & 47,1 & - \\
5 Centro & 567 & 50,8 & 48,9 & 0,3 \\
6 & 270 & 66,4 & 33,6 & - \\
7 & 174 & 62,6 & 37,4 & - \\
8 & 128 & 64,1 & 35,9 & - \\
9 & 44 & 45,2 & 52,5 & 2,2 \\
10 Derecha & 23 & 55,9 & 44,1 & - \\
N. S. & 459 & 22,5 & 77,2 & 0,2 \\
N. C. & 179 & 36,9 & 63,1 & - \\
Total & $(2.913)$ & 49,3 & 50,6 & 0,2 \\
\hline
\end{tabular}

Fuente: elaboración propia a partir de la encuesta poselectoral n. ${ }^{\circ} 3.226$ del Centro de Investigaciones Sociológicas.

Sin embargo, el mayor conocimiento y exposición no implicó mayores efectos (cambios tangibles en el comportamiento electoral) en estos comicios regionales. En términos generales, en el primer modelo estadístico de análisis (sin la intervención de los efectos de los sondeos), observamos que las dos variables más significativas para explicar el voto de los partidos fueron la ideología y las valoraciones de los diferentes candidatos. Si observamos los cambios en el modelo 2, con la introducción de la variable de los sondeos, esta solo aparece significativa en dos casos: la abstención y el voto hacia el Partido Socialista.

En ese sentido, la hipótesis 1, donde aventurábamos que la probabilidad de votar al PSOE-A sería más probable en aquellos votantes expuestos a los sondeos electorales, parece confirmarse. Una mayor exposición a estos ins- 
Gráfico 1. Efectos medios marginales de la probabilidad de votar por el PSOE-A frente a votar por Adelante Andalucía, en el subgrupo izquierda (1-4)

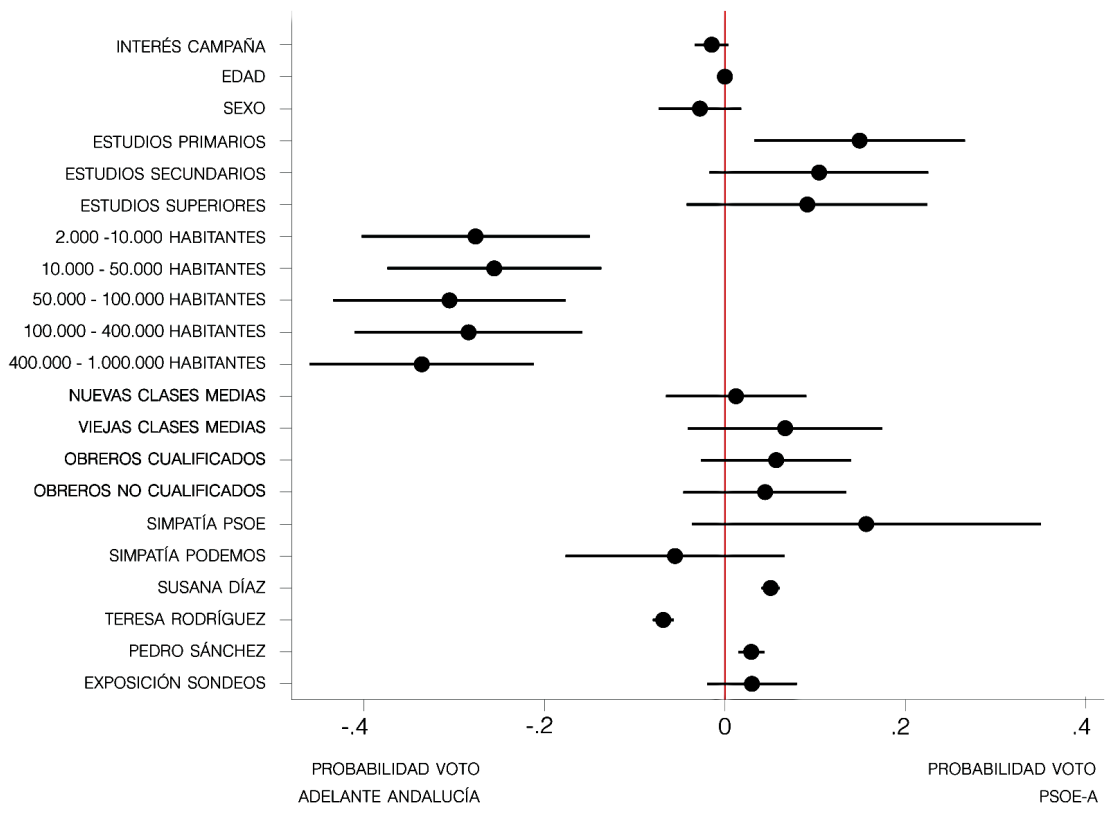

Fuente: elaboración propia a partir de la encuesta poselectoral n. ${ }^{\circ} 3.226$ del Centro de Investigaciones Sociológicas.

trumentos aumenta la posibilidad del voto a esta formación. Las encuestas funcionaron como una herramienta heurística que aportó a sus ciudadanos el partido con mayores posibilidades de formar gobierno, con relación a las tesis de Carpini (1984) y Lavrakas et al. (1991).

Por el contrario, la probabilidad de votar a Adelante estuvo mediada por otros factores, pero no por la exposición a los sondeos electorales. Más en concreto, parece que su voto está relacionado con cuestiones ideológicas (posicionamiento a la izquierda del eje), el voto urbano y el liderazgo de su candidato, pero la exposición a sondeos no es una variable estadísticamente reseñable (como apuntábamos en la subhipótesis 1.1).

Ahondando más en esta cuestión, hemos obtenido los efectos medios marginales (AME) de la probabilidad de votar al PSOE-A (1) frente a hacerlo por Adelante Andalucía (0) entre el electorado posicionado entre el 1 y el 4 del eje ideológico. Los efectos marginales permiten medir las variaciones de cada variable explicativa sobre la variable dependiente (en este caso, el voto hacia el PSOE-A o hacia Adelante Andalucía) cuando el resto de las independientes se mantienen estables, aislando sus efectos. En estos electores, se observa que la exposición a sondeos hace más probable el voto a PSOE-A frente a Adelante Andalucía, si bien su significatividad es al $82 \%$, inferior a lo estadísticamente aceptable. 
Gráfico 2. Efectos medios marginales de la probabilidad de votar por el PP frente a votar por Vox en el subgrupo derecha (6-10)

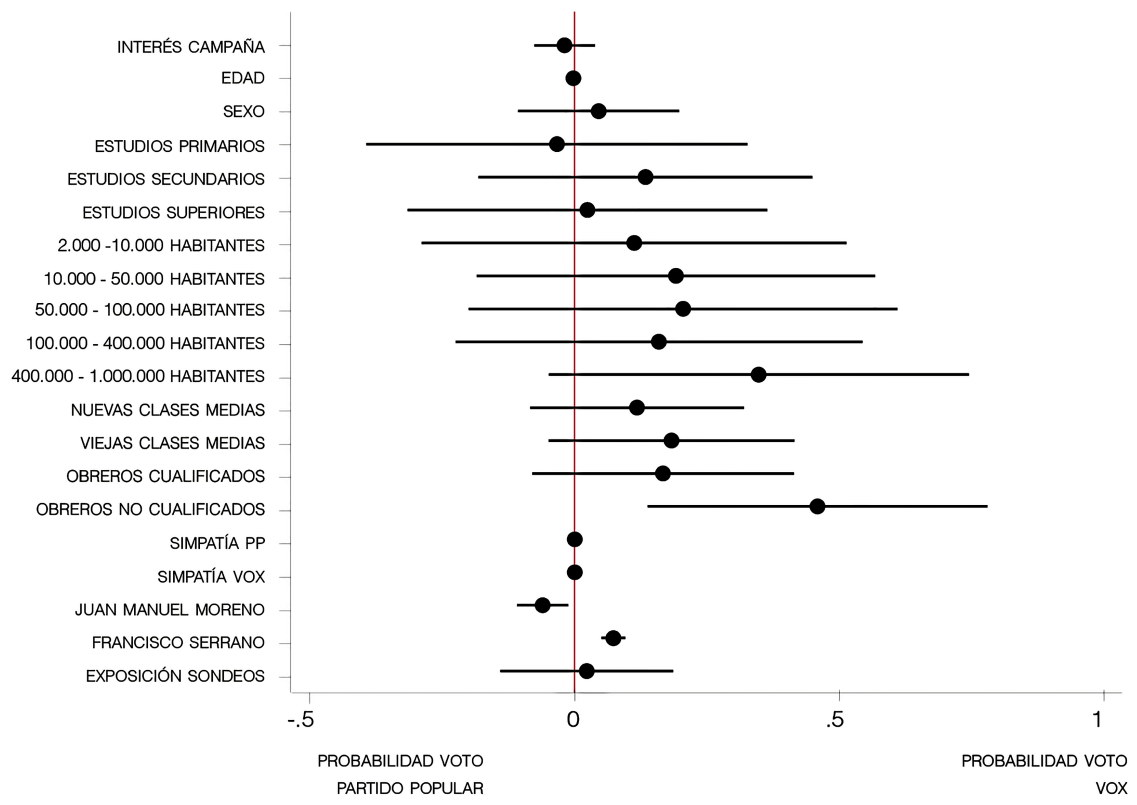

Fuente: elaboración propia a partir de la encuesta poselectoral n. ${ }^{\circ} 3.226$ del Centro de Investigaciones Sociológicas.

Descartado el voto estratégico de los votantes posicionados a la izquierda del eje ideológico, parece que no se trató de un efecto arrastre o bandwagon, sino más bien de una activación de electorado tradicionalmente ligado al Partido Socialista que se activó observando las buenas expectativas electorales que los sondeos electorales expusieron a lo largo de la campaña electoral.

Con respecto a la hipótesis 2 , los datos no confirman que la exposición a sondeos preelectorales afecte a la probabilidad de votar a Ciudadanos y al Partido Popular. Dada la alta competitividad entre los partidos en liza en el espectro conservador (Partido Popular, Ciudadanos y Vox), lo esperado sería que los votantes conservadores hubieran realizado un voto estratégico para situar al candidato con mayores posibilidades de ganar, tal y como planteaban Hopmann (2010) y Dahlgaard et al. (2016). Pero no fue así, sino que los resultados nos llevan a concluir todo lo contrario. No apreciamos datos significativos para estos dos partidos. El gran beneficiado en este escenario, a tenor de los resultados, fue Vox, en contraposición del Partido Popular y Ciudadanos, que se mantuvieron más o menos estables durante toda la campaña electoral. En ausencia de una mayoría conservadora alternativa al gobierno socialista de Susana Díaz (no olvidemos que solo uno de los sondeos ofrecía una posibilidad lejana de conformar un gobierno alternativo sin los socialistas), los electores 
Tabla 8. Probabilidad de abstención / voto a diferentes partidos en las elecciones autonómicas de 2018 en Andalucía

\begin{tabular}{|c|c|c|c|c|c|c|c|c|c|c|c|c|}
\hline \multirow[b]{2}{*}{ Variables } & \multicolumn{2}{|c|}{ Abstención } & \multicolumn{2}{|c|}{ PSOE-A } & \multicolumn{2}{|c|}{ PP } & \multicolumn{2}{|c|}{ Ciudadanos } & \multicolumn{2}{|c|}{ Adelante Andalucía } & \multicolumn{2}{|c|}{ Vox } \\
\hline & Modelo 1 & Modelo 2 & Modelo 1 & Modelo 2 & Modelo 1 & Modelo 2 & Modelo 1 & Modelo 2 & Modelo 1 & Modelo 2 & Modelo 1 & 1 Modelo 2 \\
\hline Grado interés campaña &,$- 728^{\star \star \star}$ &,$- 682^{\star \star \star}$ & ,078 &, 031 &, 062 & ,093 & 130 &, 113 &, $319^{\star \star \star}$ &, $326^{\star \star \star}$ & , 147 & ,141 \\
\hline Edad &,$- 021^{\star \star \star}$ &,$- 020^{\star \star \star}$ &, $018^{\star \star \star}$ &, $017^{\star \star \star}$ &, $016^{\star \star}$ &, $016^{\star \star}$ &,- 012 &,- 012 &,- 005 &,- 005 &,- 017 &,- 018 \\
\hline Sexo &,- 033 &,- 008 &,- 023 &,- 045 & ,006 & 024 &,- 132 &,- 142 & ,046 & ,045 & ,175 & ,160 \\
\hline \multicolumn{13}{|l|}{$\begin{array}{l}\text { Nivel de estudios } \\
\text { (ref. sin estudios) }\end{array}$} \\
\hline Primarios &,- 386 &,- 303 &, $723^{\star \star}$ &, $606^{*}$ &,- 215 &,- 188 & , 105 & ,086 & ,214 & ,224 &,- 514 &,- 485 \\
\hline Secundarios &,- 414 &,- 277 & ,257 & ,097 &,- 765 &,- 686 & ,216 & ,169 &, 523 &, 551 & 188 & ,186 \\
\hline Superiores &,- 562 &,- 388 & ,229 &, 026 &,- 754 &,- 675 & ,891 & ,844 & ,324 & ,361 &,- 249 &,- 251 \\
\hline \multicolumn{13}{|l|}{$\begin{array}{l}\text { Tamaño municipio } \\
\text { (ref. menos } 0 \text { igual } 2000 \text { hab.) }\end{array}$} \\
\hline 2.001 a 10.000 habitantes & ,282 &, 327 & $-1,001^{\star \star \star}$ & $-1,050^{\star *}$ &,- 350 &,- 332 & 879 & ,892 & 1,509 & 1,506 &,- 397 &,- 426 \\
\hline 10.001 a 50.000 habitantes & ,162 & , 186 &,- 698 &,- 709 &,- 454 &,- 452 & ,456 & ,479 & $1,506^{\star}$ & $1,497^{*}$ &,- 267 &,- 293 \\
\hline 50.001 a 100.000 habitantes & ,703 & ,738 & $-1,513^{\star \star \star}$ & $-1,548^{\star \star \star}$ &,- 486 &,- 511 &, 700 &, 721 & 1,317 & 1,312 & ,263 & ,236 \\
\hline 100.001 a 400.000 habitantes &, 504 &, 508 & $-1,261^{\star \star \star}$ & $-1,269^{\star \star}$ &,- 550 &,- 548 & ,228 & ,252 & $1,837^{\star \star}$ & $1,833^{\star \star}$ &,- 496 &,- 512 \\
\hline 400.001 a 1.000 .000 habitantes & ,390 & ,444 & $-1,467^{\star \star \star}$ & $-1,544^{\star \star \star}$ &,- 341 &,- 317 & ,668 & ,666 & $1,681^{\star \star}$ & $1,685^{\star \star}$ & ,047 & ,015 \\
\hline \multicolumn{13}{|l|}{$\begin{array}{l}\text { Estatus socioeconómico } \\
\text { (ref. clase alta/media-alta) }\end{array}$} \\
\hline Nuevas clases medias & ,278 & ,258 &,- 041 &,- 002 &,$- 662^{\star}$ &,$- 670^{\star}$ &, $534^{*}$ &, $542^{\star}$ & ,022 & ,023 &, 066 & ,062 \\
\hline Viejas clases medias &, $776^{\star \star}$ &, $739^{\star \star}$ & ,414 & ,431 &,- 496 &,- 537 & ,204 & ,222 &,- 521 &,- 522 & ,686 & ,696 \\
\hline Obreros cualificados & ,329 & ,278 & 141 & ,202 &,- 499 &,- 526 & ,287 & ,300 &,- 116 &,- 116 & $1,003^{*}$ & $1,006^{*}$ \\
\hline Obreros no cualificados &, $561^{*}$ &, $508^{\star}$ & 055 & ,124 &,- 709 &,$- 764^{*}$ & ,482 &, 505 &,- 779 &,- 779 &, 420 &, 411 \\
\hline \multicolumn{13}{|l|}{$\begin{array}{l}\text { Autoubicación ideológica } \\
\text { (ref. izquierda) }\end{array}$} \\
\hline Centro-izquierda & ,246 & ,225 &, $624^{\star \star}$ &, $675^{\star \star \star}$ &,- 493 &,- 466 & $1,446^{*}$ & $1,439^{\star}$ &,$- 703^{\star \star}$ &,$- 706^{\star \star}$ & 16,607 & 16,623 \\
\hline Centro & ,176 & , 170 &,- 234 &,- 208 & 1,471 & 1,467 & $2,223^{*}$ & $2,229^{\star \star}$ & $-2,053^{\star \star \star}$ & $-2,056^{\star \star \star}$ & 16,332 & 16,345 \\
\hline Centro-derecha &,- 360 &,- 337 & $-1,637^{\star \star \star}$ & $-1,624^{\star \star \star}$ & $2,241^{*}$ & $2,260^{*}$ & 1,361 & 1,354 & $-4,499^{\star \star \star}$ & $-4,506^{\star \star \star}$ & 17,739 & 17,739 \\
\hline Derecha &,- 613 &,- 649 & $-18,838$ & $-18,843$ & $2,489^{*}$ & $2,459^{\star}$ &,- 512 &,- 523 & $-20,195$ & $-20,189$ & 17,929 & 17,951 \\
\hline Susana Díaz (PSOE-A) &,- 014 &,- 019 &, $424^{\star \star \star}$ &, $433^{\star \star \star}$ &,$- 133^{\star \star}$ &,$- 130^{\star \star}$ &,$- 125^{\star \star}$ &,$- 124^{\star \star}$ &,$- 380^{\star \star \star}$ &,$- 381^{\star \star \star}$ & 054 & ,053 \\
\hline Juan Manuel Moreno (PP) & & & & &, $461^{\star \star \star}$ &, $458^{\star \star \star}$ & & & & & & \\
\hline Juan Marín (Ciudadanos) & & & & & & &, $490^{\star \star \star}$ &, $489^{\star \star \star}$ & & & & \\
\hline Teresa Rodríguez (AA) & & & & & & & & &, $434^{\star \star \star}$ &, $434^{\star \star \star}$ & & \\
\hline Antonio Maíllo (AA) & & & & & & & & &, $222^{\star \star \star}$ &, $223^{\star \star \star}$ & & \\
\hline Francisco Serrano (Vox) & & & & & & & & & & &, $428^{\star \star \star}$ &, $428^{\star \star \star}$ \\
\hline Pedro Sánchez (PSOE) &,- 033 &,- 027 &, $197^{\star \star \star}$ &, $196^{\star \star \star}$ &,- 045 &,- 051 &,$- 162^{\star \star \star}$ &,$- 163^{\star \star \star}$ &,- 055 &,- 055 &,$- 310^{\star \star \star}$ &,$- 307^{\star \star \star}$ \\
\hline Exposición a sondeos & &,$- 465^{\star \star \star}$ & &, $537^{\star \star \star}$ & &,- 365 & & ,195 & &,- 087 & & ,126 \\
\hline Constante & 1,159 & 1,107 & $-4,679^{\star \star \star}$ & $-4,756^{\star \star \star}$ & $-4,702^{\star \star \star}$ & $-4,622^{\star \star \star}$ & $-5,871^{\star \star \star}$ & $-5,926^{\star \star \star}$ & $-4,597^{\star *}$ & $-4,594^{\star *}$ & $-20,842$ & $-20,863$ \\
\hline Sig. & 0,000 & 0,000 & 0,000 & 0,000 & 0,000 & 0,000 & 0,000 & 0,000 & 0,000 & 0,000 & 0,000 & 0,000 \\
\hline R2 Cox y Snell & 0,149 & 0,154 & 0,367 & 0,370 & 0,297 & 0,290 & 0,207 & 0,208 & 0,379 & 0,379 & 0,216 & 0,216 \\
\hline R2 Nagelkerke & 0,236 & 0,245 & 0,555 & 0,557 & 0,512 & 0,514 & 0,354 & 0,355 & 0,626 & 0,626 & 0,465 & 0,465 \\
\hline (N) & 2071 & 2070 & 2072 & 2071 & 1489 & 1489 & 1369 & 1369 & 1152 & 1152 & 768 & 768 \\
\hline
\end{tabular}

Coeficientes de regresión. Errores estándares entre paréntesis. Significatividad: ${ }^{*} p<0.05$, ${ }^{\star *} p<0.01,{ }^{* \star *} p<0.001$.

Fuente: encuesta Poselectoral del CIS (n. $\left.{ }^{\circ} 3.226\right)$. 
parece que votaron más por motivaciones ideológicas y de representación (a quien más se aproximaba a sus creencias o preferencias) que con un voto útil para el fin requerido (voto estratégico). En ese sentido, no observamos datos para confirmar la hipótesis 3 referente al aumento de la probabilidad en aquellos votantes no expuestos, sino más bien que esta variable no afectó a su voto.

Los datos de los efectos marginales medios del siguiente gráfico son muy concluyentes en ese sentido. Confirman que en el electorado donde ambos partidos construyen sus bases de votantes el impacto de los sondeos es nulo. La probabilidad de votar al PP (0) frente a Vox (1) está inferida por las valoraciones de los candidatos, y sobre todo por segmentos concretos (obreros no cualificados).

Por último, queremos añadir una conclusión interesante que nos aportan los resultados acerca de la abstención. Las investigaciones sobre del impacto de menores recursos individuales en el retrato del votante abstencionista han sido abundantes, más concretamente en los de tipo socioeconómico (Justel, 1995; Boix y Riba, 2000), así como el impacto del género en la participación electoral, debido a que conlleva más costes para las mujeres (Santana y Aguilar, 2019). Sin embargo, como reflejan nuestros resultados, los datos sobre la menor exposición a los sondeos electorales confirman que el menor interés en la información política y de la campaña electoral afecta a la probabilidad de abstenerse.

En ese sentido, no apreciamos variables para poder ahondar en que este comportamiento (la no exposición a sondeos electorales y un aumento de la probabilidad de abstención) esté afectado por condicionamientos políticos o partidistas, sino más bien por las características clásicas (a menor edad, mayor probabilidad de abstención; también en el grupo de obreros no cualificados observamos significatividad estadística, etcétera), en línea con el menor interés en la política.

\section{Conclusiones}

En este artículo hemos intentado reflejar, dentro del clima de opinión polarizado de la campaña andaluza de 2018, los efectos que tuvieron los sondeos preelectorales en el comportamiento electoral de los ciudadanos. La investigación acerca de esta influencia ha focalizado los esfuerzos en analizar su papel dentro de las lógicas de decisión para otorgar el apoyo al candidato o partido con mayor probabilidad de ganar o que mayor rentabilidad electoral ofrece al ciudadano (voto estratégico). En línea con esto, también son abundantes los trabajos acerca del efecto arrastre como consecuencia de un clima de opinión favorable para el partido ganador.

Con relación a ambas teorías, hemos confirmado que, en línea con las tesis de Gasperoni y Mantovani (2015: 17-18), el conocimiento y la exposición a los sondeos electorales son más bien limitados y, como en el caso de la participación electoral, entran en juego los recursos individuales de los votantes (concretamente, el interés en la campaña electoral). Además, hemos testado 
un posible efecto bandwagon en el caso de los electores del Partido Socialista de Andalucía, así como la existencia de votantes que escapan a las lógicas de los climas de opinión, que son capaces de ofrecer su voto aun cuando las previsiones electorales son negativas.

En el estudio de la influencia de los sondeos, encontrar un modelo de análisis parece complejo, bien por las reticencias de los votantes al reconocimiento de su influencia en su voto, bien porque se requiere combinar un conjunto de variables que no siempre están presentes en los cuestionarios de las empresas o instituciones de demoscopia. En ese sentido, en este trabajo reconocemos dos importantes limitaciones: la ausencia de un sistema panel que permita contrastar la influencia de los sondeos, no en votantes estables, sino en aquellos que hicieron algún tipo de movimiento electoral, convertidos, activados, movilizados o desmovilizados (en términos de Anduiza y Oñate, 2003); pero también la ausencia en los cuestionarios del CIS de variables de aprobación de gestión de gobierno y políticas públicas, evaluaciones ciudadanas sobre situación económica y política, etcétera que nos hubieran permitido detallar los motivos del impacto de los sondeos en la abstención del electorado socialista. Por ejemplo, poder aseverar entre las motivaciones de los abstencionistas la existencia de un voto de castigo o simplemente motivado por causas no vinculadas a la gestión (que el propio elector no quisiera dotar de tanto poder parlamentario a este partido).

Por todo ello, debemos seguir avanzando en algunas líneas de investigación aquí apuntadas: 1) es necesario ahondar en la serie histórica para trazar si las tendencias de mayor impronta de los sondeos preelectorales en el voto de los españoles está en aumento o si las elecciones regionales en Andalucía fueron un caso aislado; 2) incidir en el binomio entre interés por la información política (y la campaña electoral) y conocimiento-exposición de sondeos preelectorales, para prever futuras correlaciones y observar cuál de las dos variables decanta a la otra; 3) analizar si en escenarios de alta competición electoral, interbloques (izquierda-derecha) o intrabloques (entre partidos del mismo bloque), los sondeos electorales tienen un papel primario o secundario en la movilización y activación electoral (en este caso, tuvieron una impronta en la decantación de los electores conservadores hacia Vox, fundamentalmente, en detrimento del Partido Popular y Ciudadanos).

\section{Referencias bibliográficas}

Anduiza, Eva y OÑate, Pablo (2003). «Los efectos de la campaña sobre los electores». En: Crespo, I. (ed.). Partidos, medios de comunicación y electores: Los efectos de la campaña electoral de 2000 en España. Valencia: Tirant lo Blanch.

BANDERA López, Noel (2016). "Qué precisión están teniendo los sondeos en el nuevo ciclo político? Elecciones europeas 2014 y autonómicas/municipales 2015». Empiria. Revista de Metodología de Ciencias Sociales (34), 124-154. <https://doi.org/10.5944/empiria.34.2016.16525>

Barreiro, Xosé; Pereira, María y García, Giselle (2015). «Los efectos sobre el voto de la campaña electoral en las elecciones europeas de 2014 en España». Revista Española de Ciencia Politica (39), 67-93. 
Bock, Harold de (1976). «Influence of in-state election poll reports on candidate preference in 1972». Journalism \& Mass Communication Quarterly, 53 (3), 457-462. <https://doi.org/10.1177/107769907605300309>

Borx, Carles y Riba, Clara (2000). «Las bases sociales y políticas de la abstención en las elecciones generales españolas: recursos individuales, movilización estratégica e instituciones electorales». Revista Española de Investigaciones Sociológicas, 90, 95-128. <https://doi.org/10.2307/40184253>

Bornschier, Simon (2010). Cleavage politics and the populist right. Filadelfia: Temple University Press.

Broughton, David (1995). Public opinion polling and politics in Britain. Londres: Prentice-Hall.

Caballé, Adrià; Grima, Pere y Marco-Almagro, Lluís (2013). “¿Aciertan los sondeos electorales? Análisis sobre la bondad de predicción de los sondeos electorales publicados en la prensa». Revista Española de Investigaciones Sociológicas (143), 25-46. <https://doi.org/10.5477/cis/reis.143.25>

Cabrera-Álvarez, Pablo y Escobar, Modesto (2019). «El efecto de la ponderación y la imputación en el sesgo de los estudios electorales en España». Revista Española de Investigaciones Sociológicas (165), 45-64. <https://doi.org/10.5477/cis/reis.165.45>

Carpini, Michael delli (1984). "Scooping the voters? The consequences of the networks' early call of the 1980 presidential race». The Journal of Politics, 46 (3), 866-885. <https://doi.org/10.2307/40184386>

Crespo, Ismael y Moreno, Cristina (2015). «Los efectos de la comunicación política en el comportamiento electoral». Revista de Derecho Electoral (20), 76-110.

Dahlgaard, Jens; Hedegaard, Jonas; Hansen, Kasper M. y Larsen, Martin V. (2016). "How are voters influenced by opinion polls? The effect of polls on voting behavior and party sympathy». World Political Science Review, 12 (2), 283-300. <https://doi.org/10.1515/wps-2016-0012>

Daschmann, Gregor (2000). «Vox pop \& polls: The impact of poll results and voter statements in the media on the perception of a climate of opinion». International Journal of Public Opinion Research, 12 (parte 2), 160-181. <https://doi.org/10.1093/ijpor/12.2.160>

Delicado, Pedro y Udina, Frederic (2001). «Cómo y cuánto fallan los sondeos electorales?». Revista Española de Investigaciones Sociológicas (96), 123-150. <https://doi.org/10.2307/40184386>

Donsbach, Wolfgang (2001). Who's Afraid of Election Polls? Normative and Empirical Arguments for the Freedom of Pre-Election Surveys. Amsterdam: Foundation for Information-Esomar

Downs, Anthony (1957). An economic theory of democracy. Nueva York: Harper and Row.

Duch, Raymond y Stevenson, Randolph (2008). The economic vote. Cambridge: Cambridge University Press. <https://doi.org/10.1017/cbo9780511755934>

Duverger, Mauricie (1954). Political Parties: Their Organization and Activity in the Modern State. Nueva York: Wiley. <https://doi.org/10.2307/2604342>

FERnÁndeZ, Elena y Vinuesa, María Lourdes (2014). «El imaginario social sobre los sondeos electorales». Revista Mexicana de Opinión Pública, 17, 70-86. <https://doi.org/10.1016/s1870-7300(14)70900-7> 
Fiorina, Morris (1981). Retrospective Voting in American National Elections. New Haven: Yale University Press. <https://doi.org/10.2307/2149903>

Font FÀbregas, Joan y Pasadas del Amo, Sara (2016). Las encuestas de opinión. Madrid: Editorial CSIC, Consejo Superior de Investigaciones Científicas.

Gallup, George y RaE, Saul (1940). The pulse of democracy: The public opinion polland how it works. Nueva York: Simon and Schuster.

Gasperoni, Giancarlo y Mantovani, Debora (2015). «The impact of exposure to preelection polls on voting behaviour». Rivista Italiana di Scienza Politica, 45 (1), 1-23. <https://doi.org/10.1017/ipo.2015.3>

Grillo, Alberto (2017). "Risk aversion and bandwagon effect in the pivotal voter model». Public Choice, 172 (3), 465-482. <https://doi.org/10.1007/s11127-017-0457-5>

Holtz-BAcha, Christina y Sтröмвӓск, Jesper (2012). Opinion polls and the media: Reflecting and shaping public opinion. Londres: Palgrave Macmillan. <https://doi.org/10.5860/choice.50-2139>

Hopmann, David Nicolas; Vliegenthart, Rens; De Vreese, Claes y Albæk, Erik (2010). «Effects of Election News Coverage: How Visibility and Tone Influence Party Choice». Political Communication, 27:4, 389-405. <https://doi.org/10.1080/10584609.2010.516798>

Hummel, Patrick (2014). «Pre-election polling and third party candidates». Social Choice and Welfare, 42 (1), 77-98. $<$ https://doi.org/10.1007/s00355-013-0724-4>

- (1995). La abstención electoral en España. Madrid: Siglo Veintiuno Ediciones. <https://doi.org/10.2307/40182838>

Key, V. O. (1966). The responsible electorate; rationality in presidential voting, 19361960. Cambridge: Harvard University Press. <https://doi.org/10.4159/harvard.9780674497764>

Kiss, Áron y Simonovits, Gábor (2014). «Identifying the bandwagon effect in tworound elections». Public Choice, 160 (3), 327-344. <https://doi.org/10.1007/s11127-013-0146-y>

Lau, Richard R. y Redlawsk, David P. (2006). How Voters Decide: Information Processing in Election Campaigns. Cambridge: Cambridge Univerity Press.

Lavrakas, Paul; Holley, Jack y Miller, Peter (1991). "Public reactions to polling news during the 1988 presidential election campaign». En: Lavrakas, Paul y Holley, Jack (eds.). Polling and presidential election coverage. Newbury Park: Sage Publications.

Lewis-Beck, Michael y Stegmaier, Mary (2009). "Learning the economic vote: Hungarian forecasts, 1998-2010». Politics \& Policy, 37 (4), 769-780. <https://doi.org/10.1111/j.1747-1346.2009.00197.x>

Likert, Rensis (1948). "Opinion studies and government policy». Proceedings of the American Philosophical Society, 92 (5), 341-350.

Maravall, José María y Przeworski, Adam (1999). «Reacciones políticas a la economía». Revista Española de Investigaciones Sociológicas, 1 (87), 11-52. <https://doi.org/10.2307/40184172>

Martínez i Coma, Ferran (2008). ¿Por qué importan las campañas electorales? Madrid: Centro de Investigaciones Sociológicas.

Mateos, Araceli y Penadés, Alberto (2013). «Las encuestas electorales en la prensa escrita (2008-2011). Errores, sesgos y transparencia». Metodología de Encuestas (15), 99-119. 
McAllister, Ian y Studlar, Donley (1991). «Bandwagon, underdog, or projection? Opinion polls and electoral choice in Britain, 1979-1987». The Journal of Politics, 53 (3), 720-741. $<$ https://doi.org/10.2307/2131577>

McEwen, Nicola (2004). «Opinion polling in Scotland: An analysis of the 2003 Scottish Parliament election». British Elections \& Parties Review, 14 (1), 171-190. <https://doi.org/10.1080/1368988042000258826>

Mehrabian, Albert (1998). "Effects of poll reports on voter preferences». Journal of Applied Social Psychology, 28 (23), 2.119-2.130. $<$ https://doi.org/10.1111/j.1559-1816.1998.tb01363.x>

Monzón, Cándido (2000). Opinión pública, comunicación y política. Madrid: Editorial Tecnos.

- (2005). Encuestas y elecciones. Madrid: Editorial Tecnos.

Moy, Patricia y Rinke, Eike (2012). "Attitudinal and behavioural consequences of published opinion polls». En: Holtz-Bacha, Christina y Sтröмвӓск, Jesper (eds.). Opinion polls and the media: Reflecting and shaping public opinion. Londres: Palgrave Macmillan.

<https://doi.org/10.1057/9780230374959.0018>

Nadeau, Richard; Niemi, Richard G. y Amato, Timothy (1994). «Expectations and preferences in British general elections». The American Political Science Review, 88 (2), 371-383.

$<$ https://doi.org/10.2307/2944710>

Noelle-Neumann, Elisabeth (1974). «The Spiral of Silence. A Theory of Public Opinion». Journal of Communication, 24 (2), 43-51. <https://doi.org/10.1111/j.1460-2466.1974.tb00367.x>

- (1984). The spiral of silence: public opinion - our social skin. Chicago: University of Chicago Press. $<$ https://doi.org/10.2307/2578842>

Obermaier, Magdalena; Koch, Thomas y Baden, Christian (2017). «Everybody follows the crowd?». Journal of Media Psychology, 29 (2), 69-80. <https://doi.org/10.1027/1864-1105/a000160>

Rich, Timothy S. (2015). «Strategic voting and the role of polls: Evidence from an embedded web survey». PS: Political Science \& Politics, 48 (2), 301-305. <https://doi.org/10.1017/s104909651400208x>

Santana, Andrés y Aguilar, S. (2019). «Heroines of the Ballot: The Gender Gap and the Costs of Voting». Social Politics: International Studies in Gender, State \& Society. <https://doi.org/10.1093/sp/jxz037>

Santana, Andrés y Rama, José (20I8) «Electoral support for left wing populist parties in Europe: addressing the globalization cleavage». European Politics and Society, 19:5, 558-576. <https://doi.org/10.1080/23745118.2018.1482848>

Skalaban, Andrew (1988). «Do the polls affect elections? Some 1980 evidence». Political Behavior, 10 (2), 136-150. <https://doi.org/10.1007/bf00991410>

STOKES, Susan (2001). Public support for market reforms in new democracies. Cambridge: Cambridge University Press. <https://doi.org/10.1017/cbo9781139175234> 